\title{
Occupational functioning and work impairment in association with personality disorder trait-scores
}

\author{
Journal Article \\ Author(s): \\ Hengartner, Michael P.; Müller, Mario; Rodgers, Stephanie; Rössler, Wulf; Ajdacic-Gross, Vladeta \\ Publication date: \\ 2014-02 \\ Permanent link: \\ https://doi.org/10.3929/ethz-b-000078051 \\ Rights / license: \\ In Copyright - Non-Commercial Use Permitted \\ Originally published in: \\ Social Psychiatry and Psychiatric Epidemiology 49(2), https://doi.org/10.1007/s00127-013-0739-2
}




\title{
Occupational functioning and work impairment in association with personality disorder trait-scores
}

\author{
Michael P. Hengartner • Mario Müller • \\ Stephanie Rodgers · Wulf Rössler • \\ Vladeta Ajdacic-Gross
}

Received: 22 May 2013/ Accepted: 28 June 2013/Published online: 9 July 2013

(c) Springer-Verlag Berlin Heidelberg 2013

\begin{abstract}
Purpose According to the DSM, functional impairment is a main criterion for the general definition of personality disorders (PDs), but research suggests that some PDs might not be related to impaired functioning. Occupational functioning has rarely been examined in all ten DSM PDs. Methods We analysed 511 adults aged 20-41 years from the general population of the canton of Zurich, Switzerland, using data from the Epidemiology Survey of the Zurich Programme for Sustainable Development of Mental Health Services. All PDs were assessed with dimensional trait-scores and associations with indicators of occupational functioning were analysed with generalised linear models.

Results Each PD revealed at least a weak association with some form of occupational impairment. Most PDs, especially from cluster $\mathrm{A}$ and $\mathrm{B}$, were significantly related to occupational dysfunction, in particular low education level, conflicts in the workplace, dismissal or demotion, and unemployment. In contrast, obsessive-compulsive PD was mostly unrelated to occupational functioning. A total personality pathology dose-response relationship was observed for low education level, conflicts in the workplace, dismissal or demotion, and unemployment.
\end{abstract}

M. P. Hengartner ( $₫) \cdot$ M. Müller · S. Rodgers · W. Rössler · V. Ajdacic-Gross

Department of Psychiatry, Psychotherapy and Psychosomatics, University of Zurich, PO Box 1930, 8021 Zurich, Switzerland e-mail: michael.hengartner@dgsp.uzh.ch

W. Rössler

Collegium Helveticum, a Joint Research Institute between the University of Zurich and the Swiss Federal Institute of

Technology, Zurich, Switzerland
Conclusions Impairment in occupational functioning is an important aspect particularly of cluster A and B PDs. Assuming that functional impairment is a predictor of illness severity, we advocate that clinicians should carefully explore indicators of occupational functioning in the diagnosis, prognosis, and treatment of PDs. The findings discussed herein have implications for general treatment, interventions in the work environment, or re-integration of patients into the labour force.

Keywords Functional impairment - Occupation . Education · Work - Epidemiology $\cdot$ Personality disorder

\section{Introduction}

Functional impairment, in particular in interpersonal and occupational areas, constitutes a major criterion of the general PD definition in DSM-5 [1], which has been adopted unchanged from DSM-IV-TR [2]. However, although it is part of the general PD definition, studies that focus comprehensively on functional impairment in all PD categories are lacking. In a previous study published in the same journal we reported on interpersonal functioning in PDs [3]. Here, we want to expand this work by focusing specifically on occupational functioning.

There are few studies available that focus on occupational dysfunction, although in sum such studies have consistently reported that PDs are associated with low qualification, educational failure, and work impairment [4-7]. Nevertheless, there is still an ongoing debate as to whether all PDs are associated with functional impairment or just specific ones [3,8]. For instance, it appears that functional impairment in obsessive-compulsive $\mathrm{PD}$ is considerably lower than in other PDs $[6,9,10]$. Some 
studies have reported that histrionic PD shows overall a high level of functionality [6, 9], although our recent analysis of associations between histrionic PD and interpersonal functioning deficits challenged that general assumption [3]. In contrast, however, it appears that borderline and schizotypal PDs are highly impairing types [3, $9,10]$.

More detailed and comprehensive studies on occupational functioning in PDs are necessary, as this is still an understudied area of research. In particular studies are lacking that include various indicators of occupational functioning instead of a single-crude global measure. Thus, the aim of the present study was to analyse different measures of occupational functioning in association with continuous measures of all DSM PD categories in a large community sample.

\section{Methods}

Study design and sampling

This study was conducted within the scope of the Epidemiology Survey of the Zurich Programme for Sustainable Development of Mental Health Services (ZInEP; in German: "Zürcher Impulsprogramm zur nachhaltigen Entwicklung der Psychiatrie"), a research and health care programme involving several psychiatric research divisions and mental health services of the canton of Zurich, Switzerland. The epidemiology survey is one of the six ZInEP subprojects and consists of four components: (1) a short telephone screening, (2) a comprehensive semi-structured face-to-face interview followed by self-report questionnaires, (3) tests in the sociophysiological laboratory, and (4) a longitudinal survey (see Fig. 1). The telephone screening and semi-structured interviews started in August 2010 , the tests at the sociophysiological laboratory in February 2011, and the longitudinal survey in April 2011. The screening ended in May 2012 and all other components in September 2012.

First, a total of 9,829 Swiss males and females aged 20-41 years at the onset of the survey and considered representative of the general population of the canton of Zurich, Switzerland, were screened by computer-assisted telephone interview (CATI) using the symptom checklist 27 (SCL-27) [11]. All participants were randomly chosen through the resident registration offices of all municipalities of the canton of Zurich. Residents without Swiss nationality were excluded from the study. The CATI was conducted by growth for knowledge (GfK), a major market and field research institute, in accordance with instructions from the ZInEP research team. The overall response rate was $53.6 \%$. Reasons for non-response

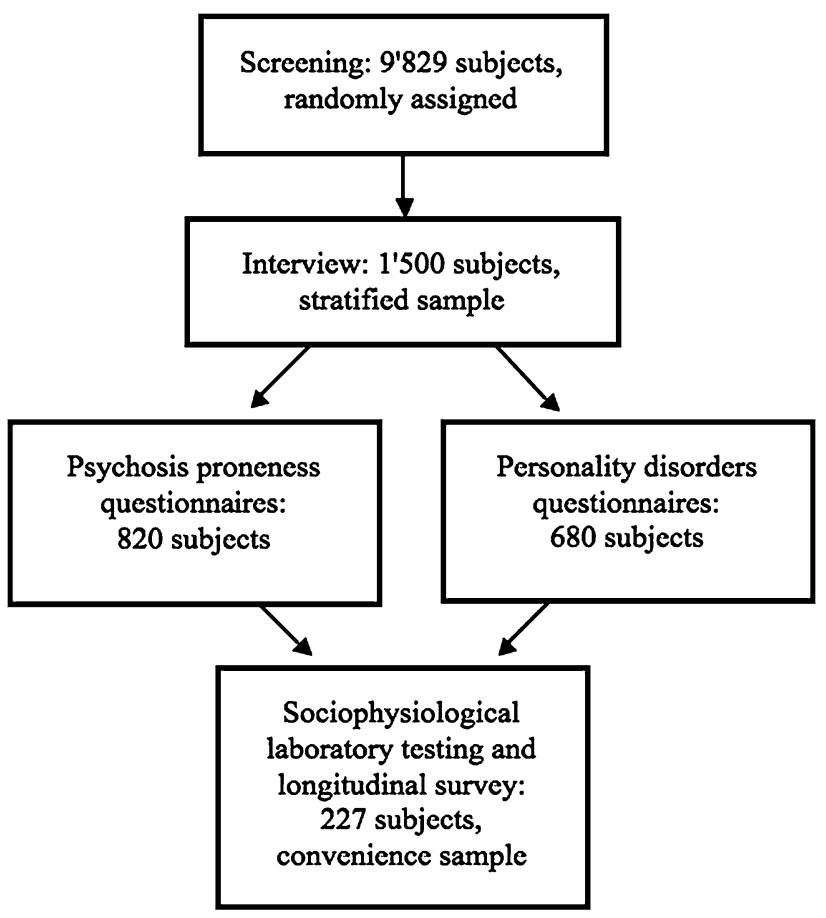

Fig. 1 The design of the ZInEP epidemiology survey

were no response, only telephone responder, incorrect telephone number, communication impossible, unavailability during the study period, or refusal by a third person or the target person. In cases where potential subjects were available by telephone, the response rate was $73.9 \%$.

Second, 1,500 subjects were randomly selected from the initial screening sample for subsequent face-to-face interviews (response rate: $65.2 \%$ ). We applied a stratified sampling procedure including $60 \%$ high-scorers (scoring above the 75th percentile of the global severity index of the SCL-27) and $40 \%$ low-scorers (scoring below the 75th percentile of the global severity index). The basic sampling design was adapted from the longitudinal Zurich cohort study [12] and was chosen to enrich the sample with subjects at high risk of mental disorders. Such a two-phase procedure with initial screening and subsequent interview with a stratified subsample is fairly common in epidemiological surveys [13].

Face-to-face interviews were conducted by experienced and extensively trained clinical psychologists. The interviews took place either at the participants' homes or at the University Hospital of Psychiatry in Zurich. All participants who completed the semi-structured interview were required to complete additional questionnaires. For this purpose, the sample was randomly divided into subsamples focusing either on psychosis $(N=820)$ or on PDs $(N=680)$. Out of a total of 680 subjects in the subsample focusing on PDs, $169(24.9 \%)$ refused to 
return or to complete all questionnaires required for the present study, resulting in a reduced final sample size of $N=511$ (284 females; 227 males; mean age: $29.6 \pm 6.7$ years).

The ZInEP epidemiology survey was approved by the Zurich State Ethical Committee (KEK) as fulfilling all legal and data privacy protection requirements and is in strict accordance with the declaration of Helsinki of the world medical association. All participants gave their written informed consent.

\section{Instruments and measures}

To measure dimensional PD trait-scores we used the assessment of DSM-IV personality disorders questionnaire (ADP-IV) [14]. For the ZInEP epidemiology survey the German translation by Doering et al. [15] was used. The ADP-IV design allows a dimensional trait-score and a categorical PD diagnosis for each of the DSM-IV PDs. The ADP-IV is a paper-pencil self-report instrument consisting of 94 items representing the 80 criteria of the 10 DSM-IV PDs and the 14 research criteria of the depressive and the passive-aggressive PDs. Each trait-question is rated on a seven-point Likert scale, ranging from "totally disagree" to "totally agree". Internal consistency of the ADP-IV dimensional PD scales is good $[15,16]$ and test-retest reliability and concurrent validity of the dimensional ADPIV trait-scores are also satisfactory $[15,16]$. Most importantly, the ADP-IV showed good concordance with the SCID-II interview [17] and may be considered an economic and valid alternative to semi-structured interviews.

Education level (high vs. low), participation in the labour force (in vs. out), employment (full-time vs. parttime), and position (management vs. normal) were assessed during the CATI. Labour force and employment were presented with standardised response options. Education level was assessed by asking the participants to indicate their highest educational degree. In Switzerland there are many educational qualifications that do not have exact equivalents in the US or in other countries. These qualifications were subsequently categorised as low (if the highest form corresponded to a high school diploma) and high (if it corresponded to college or higher). Position was coded according to participants' job specification. All other indicators of occupational functioning were assessed with a checklist that was handed out along with the other questionnaires. That instrument contained a detailed list of various life events, including conflicts in the workplace, resigning from a job, dismissal from a job, demotion in a job, or unemployment. Participants were advised to mark all events that occurred in their life during the past 12 months.
Statistical analysis

First, because values on all continuous PD trait-scores were missing completely at random (MCAR) according to little's MCAR test $\left(\chi^{2}=46.908, \mathrm{df}=53, p=0.709\right)$ we conducted a missing value analysis (MVA). No variable was missing in more than maximally nine subjects $(1.8 \%)$. MVA was carried out with the full information maximum likelihood estimation, an MVA procedure recommended by Schafer and Graham [18]. The associations between indicators of occupational functioning and PD trait-scores were analysed with a series of generalised linear models. The dichotomous measures of occupational functioning were entered as the dependent variables; thus, we fitted models with binomial distribution and logit-link function. A robust estimator was applied to reduce the effects of outliers and influential observations. All PD trait-scores were standardised using the $z$-transformation, in order that the odds ratio (OR) referred to a one standard deviation increase along the respective PD dimension. As a consequence some associations may appear rather modest. However, an OR of 1.50 for a one standard deviation increase corresponds to an OR of 2.25 for a two standard deviation increase, which represents a medium effect size. Considering that $2.3 \%$ of a population score higher than two standard deviations above the mean in a normally distributed trait, this reference is still higher than the average prevalence of each PD category in the general population. Because occupation is highly dependant on age and sex we adjusted all associations for those two confounders. All analyses were conducted with SPSS 20 for Macintosh.

\section{Results}

The results for cluster A PDs are reported in Table 1. Paranoid PD was associated with low education level, full time employment, conflicts in the workplace, dismissal or demotion, and unemployment. Full-time employment was uniquely related to paranoid PD. Schizoid PD was related to low education level, dismissal or demotion, and unemployment. The association with dismissal or demotion was particularly high. Schizotypal PD was related to low education level, being out of the labour force, conflicts in the workplace, dismissal or demotion, and unemployment. It is the only PD type that was associated with being out of the labour force.

The associations with cluster B PDs are indicated in Table 2. Antisocial PD was related only to low education level and conflicts in the workplace. Borderline PD was associated with low education level, conflicts in the workplace, dismissal or demotion, and unemployment. As 
Table 1 Associations of occupational functioning with cluster A PDs, adjusted for sex and age

\begin{tabular}{|c|c|c|c|c|c|c|}
\hline & \multicolumn{2}{|l|}{ Paranoid PD } & \multicolumn{2}{|l|}{ Schizoid PD } & \multicolumn{2}{|l|}{ Schizotypal PD } \\
\hline & OR $(95 \% \mathrm{CI})$ & Sig. & OR $(95 \% \mathrm{CI})$ & Sig. & OR $(95 \% \mathrm{CI})$ & Sig. \\
\hline \multicolumn{7}{|l|}{ Education level } \\
\hline Low $(N=302)$ & $1.30(1.07 ; 1.57)$ & 0.008 & $1.31(1.07 ; 1.60)$ & 0.009 & $1.43(1.17 ; 1.75)$ & 0.001 \\
\hline $\operatorname{High}(N=208)$ & Reference & & Reference & & Reference & \\
\hline \multicolumn{7}{|l|}{ Labour force } \\
\hline Out $(N=109)$ & $1.13(0.89 ; 1.44)$ & 0.301 & $1.19(0.94 ; 1.49)$ & 0.150 & $1.26(1.01 ; 1.58)$ & 0.041 \\
\hline In $(N=402)$ & Reference & & Reference & & Reference & \\
\hline \multicolumn{7}{|l|}{ Employment } \\
\hline Full time $(N=255)$ & 1.34 (1.06; 1.69) & 0.015 & $1.08(0.85 ; 1.36)$ & 0.546 & $1.15(0.91 ; 1.45)$ & 0.244 \\
\hline Part time $(N=147)$ & Reference & & Reference & & Reference & \\
\hline \multicolumn{7}{|l|}{ Position } \\
\hline Management $(N=43)$ & $0.88(0.62 ; 1.26)$ & 0.486 & $0.97(0.69 ; 1.35)$ & 0.837 & $0.66(0.43 ; 1.03)$ & 0.067 \\
\hline Normal $(N=346)$ & Reference & & Reference & & Reference & \\
\hline \multicolumn{7}{|l|}{ Conflicts in workplace } \\
\hline Yes $(N=161)$ & $1.72(1.38 ; 2.13)$ & 0.000 & $1.13(0.92 ; 1.38)$ & 0.263 & $1.71(1.39 ; 2.11)$ & 0.000 \\
\hline No $(N=253)$ & Reference & & Reference & & Reference & \\
\hline \multicolumn{7}{|l|}{ Resignation } \\
\hline Yes $(N=89)$ & $1.13(0.89 ; 1.43)$ & 0.331 & $0.84(0.64 ; 1.10)$ & 0.203 & $1.12(0.88 ; 1.42)$ & 0.367 \\
\hline No $(N=329)$ & Reference & & Reference & & Reference & \\
\hline \multicolumn{7}{|l|}{ Dismissal or demotion } \\
\hline Yes $(N=34)$ & $1.53(1.17 ; 1.98)$ & 0.002 & $1.97(1.44 ; 2.71)$ & 0.000 & $1.64(1.19 ; 2.27)$ & 0.002 \\
\hline No $(N=378)$ & Reference & & Reference & & Reference & \\
\hline \multicolumn{7}{|l|}{ Unemployment } \\
\hline Yes $(N=49)$ & $1.50(1.19 ; 1.90)$ & 0.001 & $1.45(1.13 ; 1.87)$ & 0.003 & $1.49(1.17 ; 1.90)$ & 0.001 \\
\hline No $(N=462)$ & Reference & & Reference & & Reference & \\
\hline
\end{tabular}

Statistically significant associations $(p<0.05)$ are indicated in bold

$P D$ personality disorder, $O R$ odds ratio, $C I$ confidence interval, Sig. statistical significance

in schizoid PD the association with dismissal or demotion was particularly strong. Histrionic PD was related to low education level and conflicts in the workplace, and narcissistic PD was exclusively associated with conflicts in the workplace.

The results for cluster C PDs are presented in Table 3. Notably, no cluster C PD was associated with education level. Avoidant PD was related to dismissal or demotion, and unemployment. Dependant PD was associated with conflicts in the workplace and dismissal or demotion, and obsessive-compulsive PD was uniquely and weakly related to conflicts in the workplace.

Both the cluster A and B trait-scores were associated with low education level, conflicts in the workplace, dismissal or demotion, and unemployment. The cluster $\mathrm{C}$ trait-score was uniquely related to conflicts in the workplace and dismissal or demotion. Moreover, in cluster $\mathrm{C}$ the strength of association in those measures was markedly lower than in cluster A or B. The total PD trait-score was again significantly associated with low education level, conflicts in the workplace, dismissal or demotion, and unemployment, which indicates a dose-response relationship in those variables (see Table 4).

\section{Discussion}

In this study we carried out a detailed analysis of occupational functioning in relation to all DSM-5 PD categories using data from the general population. Overall, each PD revealed at least a weak association with some form of occupational impairment. Most PDs, especially those from cluster A and B, were significantly and consistently related to occupational dysfunction, in particular low education level, conflicts in the workplace, dismissal or demotion, and unemployment. Those findings are in line with the literature [4-7].

Nevertheless, we noted some striking peculiarities. Cluster C PDs were overall less strongly related to occupational dysfunction than the other PDs. Moreover, unlike 
Table 2 Associations of occupational functioning with cluster B PDs, adjusted for sex and age

\begin{tabular}{|c|c|c|c|c|c|c|c|c|}
\hline & \multicolumn{2}{|l|}{ Antisocial PD } & \multicolumn{2}{|l|}{ Borderline PD } & \multicolumn{2}{|l|}{ Histrionic PD } & \multicolumn{2}{|l|}{ Narcissistic PD } \\
\hline & OR $(95 \% \mathrm{CI})$ & Sig. & OR $(95 \% \mathrm{CI})$ & Sig. & OR $(95 \% \mathrm{CI})$ & Sig. & OR $(95 \%$ CI $)$ & Sig. \\
\hline \multicolumn{9}{|l|}{ Education level } \\
\hline Low $(N=302)$ & $1.49(1.19 ; 1.85)$ & 0.000 & $1.49(1.20 ; 1.86)$ & 0.000 & $1.31(1.08 ; 1.58)$ & 0.005 & $1.20(1.00 ; 1.46)$ & 0.056 \\
\hline $\operatorname{High}(N=208)$ & Reference & & Reference & & Reference & & Reference & \\
\hline \multicolumn{9}{|l|}{ Labour force } \\
\hline Out $(N=109)$ & $1.20(0.96 ; 1.49)$ & 0.103 & $1.06(0.83 ; 1.36)$ & 0.623 & $1.11(0.90 ; 1.38)$ & 0.337 & $1.17(0.94 ; 1.46)$ & 0.154 \\
\hline In $(N=402)$ & Reference & & Reference & & Reference & & Reference & \\
\hline \multicolumn{9}{|l|}{ Employment } \\
\hline Full time $(N=255)$ & $0.91(0.71 ; 1.15)$ & 0.409 & $1.01(0.80 ; 1.27)$ & 0.945 & $1.05(0.85 ; 1.28)$ & 0.669 & $1.12(0.91 ; 1.39)$ & 0.290 \\
\hline Part time $(N=147)$ & Reference & & Reference & & Reference & & Reference & \\
\hline \multicolumn{9}{|l|}{ Position } \\
\hline Management $(N=43)$ & $0.86(0.61 ; 1.23)$ & 0.411 & $0.85(0.59 ; 1.22)$ & 0.379 & $0.79(0.56 ; 1.10)$ & 0.164 & $0.90(0.64 ; 1.26)$ & 0.531 \\
\hline Normal $(N=346)$ & Reference & & Reference & & Reference & & Reference & \\
\hline \multicolumn{9}{|l|}{ Conflicts in workplace } \\
\hline Yes $(N=161)$ & $1.24(1.02 ; 1.52)$ & $\mathbf{0 . 0 3 3}$ & 1.61 (1.30; 1.99) & 0.000 & $1.46(1.19 ; 1.78)$ & 0.000 & $1.41(1.16 ; 1.71)$ & 0.001 \\
\hline No $(N=253)$ & Reference & & Reference & & Reference & & Reference & \\
\hline \multicolumn{9}{|l|}{ Resignation } \\
\hline Yes $(N=89)$ & $1.20(0.95 ; 1.50)$ & 0.123 & $1.12(0.87 ; 1.43)$ & 0.374 & $1.12(0.89 ; 1.41)$ & 0.344 & $1.04(0.82 ; 1.32)$ & 0.746 \\
\hline No $(N=329)$ & Reference & & Reference & & Reference & & Reference & \\
\hline \multicolumn{9}{|l|}{ Dismissal or demotion } \\
\hline Yes $(N=34)$ & $1.27(0.90 ; 1.80)$ & 0.180 & $1.99(1.42 ; 2.79)$ & 0.000 & $1.24(0.87 ; 1.77)$ & 0.234 & $1.35(0.99 ; 1.83)$ & 0.058 \\
\hline No $(N=378)$ & Reference & & Reference & & Reference & & Reference & \\
\hline \multicolumn{9}{|l|}{ Unemployment } \\
\hline Yes $(N=49)$ & $1.27(0.98 ; 1.65)$ & 0.068 & $1.41(1.11 ; 1.80)$ & 0.005 & $1.10(0.81 ; 1.50)$ & 0.531 & $1.27(0.98 ; 1.65)$ & 0.066 \\
\hline No $(N=462)$ & Reference & & Reference & & Reference & & Reference & \\
\hline
\end{tabular}

Statistically significant associations $(p<0.05)$ are indicated in bold

$P D$ personality disorder, $O R$ odds ratio, $C I$ confidence interval, Sig. statistical significance

clusters $\mathrm{A}$ and $\mathrm{B}$, no single cluster $\mathrm{C}$ PD revealed a significant association with education level. In contrast to our previous report focusing on interpersonal dysfunction [3] we did not find that borderline and schizotypal PDs were outstandingly related to occupational dysfunction, suggesting that functional impairment differentiates borderline and schizotypal PD from the other PD categories [10] with respect to interpersonal relations rather than relating to job performance or educational achievement. A similar pattern with an outstandingly high association with schizotypal and borderline PDs emerged for childhood adversity [19, 20], which may potentially serve as an indicator of the dysfunctionality and severity of those two PDs (although not apparent in all areas) [8]. The high functional impairment attributed to schizotypal and borderline PDs has also been emphasised by others [10]. In addition to mental disorders it has been shown that childhood adversity causes severe functional impairment in various social domains $[21,22]$. However, whether childhood adversity has a specific detrimental effect on (interpersonal) functional impairment in some PD dimensions needs to be addressed in future studies.

In contrast to studies reporting that histrionic PD shows a generally high level of functionality $[6,9]$ we found that this type is also related to functional impairment, especially with respect to conflicts in the workplace, but also to low education level. This finding is in line with associations between histrionic PD and interpersonal functioning deficits, which we have reported previously [3]. Therefore, we decidedly advocate against the underestimation and neglect of histrionic traits. It is important to note that this PD type is associated with significant impairment in social functioning as well.

Our results also provide further evidence that obsessivecompulsive PD is only weakly related to occupational impairment and that its functional impairment is particularly lower than in cluster A or B PDs $[6,9,10]$. Thus, obsessive-compulsive PD appears to be less related to functional impairment or global quality of life as compared to other PDs, although we still found some important 
Table 3 Associations of occupational functioning with cluster C PDs, adjusted for sex and age

\begin{tabular}{|c|c|c|c|c|c|c|}
\hline & \multicolumn{2}{|l|}{ Avoidant } & \multicolumn{2}{|l|}{ Dependant } & \multicolumn{2}{|l|}{ Obs.-comp. } \\
\hline & OR $(95 \% \mathrm{CI})$ & Sig. & OR $(95 \% \mathrm{CI})$ & Sig. & OR $(95 \% \mathrm{CI})$ & Sig. \\
\hline \multicolumn{7}{|l|}{ Education level } \\
\hline Low $(N=302)$ & $1.17(0.96 ; 1.43)$ & 0.129 & $1.10(0.91 ; 1.33)$ & 0.341 & $1.01(0.84 ; 1.22)$ & 0.909 \\
\hline High $(N=208)$ & Reference & & Reference & & Reference & \\
\hline \multicolumn{7}{|l|}{ Labour force } \\
\hline Out $(\underline{N}=109)$ & $1.18(0.95 ; 1.48)$ & 0.139 & $1.15(0.93 ; 1.42)$ & 0.196 & $1.09(0.87 ; 1.35)$ & 0.462 \\
\hline In $(N=402)$ & Reference & & Reference & & Reference & \\
\hline \multicolumn{7}{|l|}{ Employment } \\
\hline Full time $(N=255)$ & $0.98(0.79 ; 1.23)$ & 0.876 & $0.93(0.75 ; 1.15)$ & 0.500 & $1.10(0.89 ; 1.35)$ & 0.397 \\
\hline Part time $(N=147)$ & Reference & & Reference & & Reference & \\
\hline \multicolumn{7}{|l|}{ Position } \\
\hline Management $(N=43)$ & $0.88(0.62 ; 1.26)$ & 0.493 & $0.92(0.67 ; 1.27)$ & 0.605 & $1.03(0.79 ; 1.35)$ & 0.819 \\
\hline Normal $(N=346)$ & Reference & & Reference & & Reference & \\
\hline \multicolumn{7}{|l|}{ Conflicts in workplace } \\
\hline Yes $(N=161)$ & $1.21(0.98 ; 1.48)$ & 0.072 & 1.31 (1.07; 1.60) & 0.008 & $1.25(1.03 ; 1.53)$ & 0.027 \\
\hline No $(N=253)$ & Reference & & Reference & & Reference & \\
\hline \multicolumn{7}{|l|}{ Resignation } \\
\hline Yes $(N=89)$ & $0.92(0.71 ; 1.19)$ & 0.521 & $0.85(0.65 ; 1.11)$ & 0.225 & $1.04(0.83 ; 1.31)$ & 0.739 \\
\hline No $(N=329)$ & Reference & & Reference & & Reference & \\
\hline \multicolumn{7}{|l|}{ Dismissal or demotion } \\
\hline Yes $(N=34)$ & $1.50(1.10 ; 2.05)$ & 0.010 & $1.63(1.20 ; 2.20)$ & 0.002 & $1.10(0.81 ; 1.50)$ & 0.551 \\
\hline No $(N=378)$ & Reference & & Reference & & Reference & \\
\hline \multicolumn{7}{|l|}{ Unemployment } \\
\hline Yes $(N=49)$ & $1.33(1.01 ; 1.75)$ & 0.039 & $1.27(0.94 ; 1.71)$ & 0.114 & $1.05(0.81 ; 1.35)$ & 0.732 \\
\hline No $(N=462)$ & Reference & & Reference & & Reference & \\
\hline
\end{tabular}

Statistically significant associations $(p<0.05)$ are indicated in bold

$P D$ personality disorder, $O R$ odds ratio, $C I$ confidence interval, Sig. statistical significance

associations with interpersonal functioning deficits that should not be ignored [3]. However, in occupational areas subjects with obsessive-compulsive traits appear to function quite well. We hypothesise that this high level of occupational functioning is closely linked to the trait conscientiousness, which underlies facets of obsessivecompulsive PD [23, 24]. Conscientiousness in turn has proven to be a substantial predictor of job performance, educational achievement, and academic success [25-27]. Thus, it may be that although subjects exhibit maladaptive obsessive-compulsive symptoms which could potentially impair their occupational functioning according to DSM criteria [2], their high conscientiousness, expressed through abilities like diligence, carefulness, and steadiness, prevents them from failing in occupational areas.

PDs may be conceived of as extreme manifestations on normal personality traits [28]. Presumably the most important personality trait underlying PD symptomatology is neuroticism [29]. Consequently, neuroticism is an important predictor of occupational impairment [30, 31] and health care utilisation [32, 33]. It has also been demonstrated that functional impairment predicts health care utilisation independently of the occurrence of any mental disorder [34, 35]. In connection with the findings elucidated above it is thus not any more surprising that the prevalence of PDs is as high as $30-50 \%$ in primary care settings and specialised mental health services, while it is 4-12\% in the general population [36]. It has also been shown that PD traits as well as general personality traits independently predict treatment utilisation [37]. Ten Have et al. [33] argued that subjects high in neuroticism, such as typically borderline patients, are highly vulnerable to stress and lack appropriate coping strategies. For those subjects professional health services often represent the last resort. In contrast, antagonistic and antisocial subjects use professional treatment less, supposedly because of the external attribution of their difficulties and distress (i.e. blaming others for their problems) [37]. Interestingly, the present study also demonstrated that except for low education level, antisocial PD was only weakly associated with 
Table 4 Associations of occupational functioning with PD cluster scores and total PD trait-score, adjusted for sex and age

\begin{tabular}{|c|c|c|c|c|c|c|c|c|}
\hline & \multicolumn{2}{|l|}{ Cluster A score } & \multicolumn{2}{|l|}{ Cluster B score } & \multicolumn{2}{|l|}{ Cluster C score } & \multicolumn{2}{|l|}{ Total score } \\
\hline & OR $(95 \%$ CI $)$ & Sig. & OR $(95 \% \mathrm{CI})$ & Sig. & OR $(95 \% \mathrm{CI})$ & Sig. & OR $(95 \%$ CI $)$ & Sig. \\
\hline \multicolumn{9}{|l|}{ Education level } \\
\hline Low $(N=302)$ & 1.42 (1.16; 1.74) & 0.001 & 1.44 (1.18; 1.76) & 0.000 & $1.11(0.92 ; 1.35)$ & 0.291 & $1.35(1.10 ; 1.64)$ & 0.003 \\
\hline $\operatorname{High}(N=208)$ & Reference & & Reference & & Reference & & Reference & \\
\hline \multicolumn{9}{|l|}{ Labour force } \\
\hline Out $(N=109)$ & $1.23(0.98 ; 1.56)$ & 0.081 & $1.15(0.92 ; 1.45)$ & 0.224 & $1.17(0.94 ; 1.45)$ & 0.169 & $1.20(0.95 ; 1.51)$ & 0.121 \\
\hline In $(N=402)$ & Reference & & Reference & & Reference & & Reference & \\
\hline \multicolumn{9}{|l|}{ Employment } \\
\hline Full time $(N=255)$ & $1.23(0.98 ; 1.56)$ & 0.078 & $1.03(0.83 ; 1.28)$ & 0.784 & $1.00(0.81 ; 1.24)$ & 0.993 & $1.08(0.87 ; 1.34)$ & 0.493 \\
\hline Part time $(N=147)$ & Reference & & Reference & & Reference & & Reference & \\
\hline \multicolumn{9}{|l|}{ Position } \\
\hline Management $(N=43)$ & $0.79(0.53 ; 1.18)$ & 0.246 & $0.80(0.56 ; 1.16)$ & 0.246 & $0.94(0.68 ; 1.29)$ & 0.680 & $0.83(0.58 ; 1.20)$ & 0.318 \\
\hline Normal $(N=346)$ & Reference & & Reference & & Reference & & Reference & \\
\hline \multicolumn{9}{|l|}{ Conflicts in workplace } \\
\hline Yes $(N=161)$ & $1.64(1.33 ; 2.03)$ & 0.000 & $1.54(1.25 ; 1.89)$ & 0.000 & $1.29(1.06 ; 1.58)$ & 0.013 & $1.54(1.25 ; 1.89)$ & 0.000 \\
\hline No $(N=253)$ & Reference & & Reference & & Reference & & Reference & \\
\hline \multicolumn{9}{|l|}{ Resignation } \\
\hline Yes $(N=89)$ & $1.04(0.81 ; 1.34)$ & 0.759 & $1.14(0.90 ; 1.44)$ & 0.290 & $0.93(0.72 ; 1.19)$ & 0.549 & $1.04(0.81 ; 1.33)$ & 0.769 \\
\hline No $(N=329)$ & Reference & & Reference & & Reference & & Reference & \\
\hline \multicolumn{9}{|l|}{ Dismissal or demotion } \\
\hline Yes $(N=34)$ & 1.95 (1.44; 2.62) & 0.000 & $1.58(1.13 ; 2.20)$ & 0.007 & $1.48(1.09 ; 2.02)$ & 0.013 & $1.74(1.26 ; 2.41)$ & 0.001 \\
\hline No $(N=378)$ & Reference & & Reference & & Reference & & Reference & \\
\hline \multicolumn{9}{|l|}{ Unemployment } \\
\hline Yes $(N=49)$ & $1.59(1.26 ; 2.01)$ & 0.000 & $1.32(1.03 ; 1.70)$ & 0.028 & $1.26(0.96 ; 1.66)$ & 0.093 & $1.42(1.11 ; 1.82)$ & 0.005 \\
\hline No $(N=462)$ & Reference & & Reference & & Reference & & Reference & \\
\hline
\end{tabular}

Statistically significant associations $(p<0.05)$ are indicated in bold

$P D$ personality disorder, $O R$ odds ratio, $C I$ confidence interval, Sig. statistical significance

occupational impairment. Thus, apparently antisocial individuals lack psychological strain, which would also provide an alternative explanation for why they use treatment less. Bearing those findings in mind, our results further emphasise the implications of maladaptive personality traits, with PDs as their extreme variants, for public mental health policies as further detailed below.

Although inconclusive, some research evidence suggests that the functional impairment of subjects with PDs is comparable to that of subjects with schizophrenia and that impairment related to PDs is considerably higher than in mood or anxiety disorders [38, 39]. Functional impairment also plays an important role in classifying PDs according to their severity $[8,36]$. It has been suggested that severity is directly related to functional impairment. In this respect we found a dose-response relationship of the total PD traitscore for education, conflicts in the workplace, dismissal or demotion, and unemployment. The sum of total PD traits or symptoms is regarded as a valid indicator of PD severity [8]. As a consequence functional impairment would allow for inference on severity, which makes it a valuable indicator in clinical practice. In accordance with this hypothesis Rymaszewska et al. [38] found that symptom severity was the best predictor of social disability (including occupational dysfunction) in a large multisite study. We therefore advocate that clinicians should carefully assess indicators of occupational functioning and educational achievement for the diagnosis and prognosis of a PD. Considering occupation and education as resilience factors may provide further implications for prevention and intervention [20]. Exploration of PD symptoms and traits would be particularly meaningful with regard to interventions in the work environment or re-integration into the labour force.

Despite the strengths of a large community sample and elaborate assessment of occupational functioning in association with continuous measures of all ten DSM PDs, this study is also subject to one major limitation. Because of the cross-sectional design this study is strictly correlational in nature and we cannot draw causal conclusions from our 
data. In addition we acknowledge the reduced response rate. Assuming that more severely ill people are harder to access and less willing to participate, we cannot exclude a certain bias in this respect. Furthermore, all data in the present study relied on self-reports, which implies that our results may be biased through omission, denial, or concealment.

Acknowledgments ZInEP was supported by a private donation. The donor had no further role in the experimental design, the collection, analysis, and interpretation of data, the writing of this report, or the decision to submit this paper for publication.

Conflict of interest On behalf of all authors, the corresponding author states that there is no conflict of interest.

\section{References}

1. American Psychiatric Association (2013) Diagnostic and statistical manual of mental disorders DSM-5. American Psychiatric Association, Washington

2. American Psychiatric Association (2000) Diagnostic and statistical manual of mental disorders DSM-IV-TR. American Psychiatric Association, Washington

3. Hengartner MP, Müller M, Rodgers S, Rössler W, Ajdacic-Gross V (2013) Interpersonal functioning deficits in association with DSM-IV personality disorder dimensions. Soc Psychiatry Psychiatr Epidemiol. doi:10.1007/s00127-013-0707-x

4. Coid J, Yang M, Tyrer P, Roberts A, Ullrich S (2006) Prevalence and correlates of personality disorder in Great Britain. $\mathrm{Br} \mathrm{J}$ Psychiatry 188:423-431

5. Johnson JG, First MB, Cohen P, Skodol AE, Kasen S, Brook JS (2005) Adverse outcomes associated with personality disorder not otherwise specified in a community sample. Am J Psychiatry 162:1926-1932

6. Oltmanns TF, Melley AH, Turkheimer E (2002) Impaired social functioning and symptoms of personality disorders assessed by peer and self-report in a nonclinical population. J Pers Disord $16: 437-452$

7. Torgersen S, Kringlen E, Cramer V (2001) The prevalence of personality disorders in a community sample. Arch Gen Psychiatry 58:590-596

8. Crawford MJ, Koldobsky N, Mulder R, Tyrer P (2011) Classifying personality disorder according to severity. J Pers Disord 25:321-330

9. Cramer V, Torgersen S, Kringlen E (2006) Personality disorders and quality of life. A population study. Compr Psychiatry 47: 178-184

10. Skodol AE, Gunderson JG, McGlashan TH, Dyck IR, Stout RL, Bender DS, Grilo CM et al (2002) Functional impairment in patients with schizotypal, borderline, avoidant, or obsessivecompulsive personality disorder. Am J Psychiatry 159:276-283

11. Hardt J, Egle UT, Kappis B, Hessel A, Brähler E (2004) Symptom Checklist SCL-27: results of a representative German survey. Psychother Psych Med 54:214-223

12. Angst J, Gamma A, Neuenschwander M, Ajdacic-Gross V, Eich D, Rössler W, Merikangas KR (2005) Prevalence of mental disorders in the Zurich cohort study: a twenty year prospective study. Epidemiol Psichiatr Soc 14:68-76

13. Dunn G, Pickles A, Tansella M, Vazquez-Barquero JL (1999) Two-phase epidemiological surveys in psychiatric research. Br J Psychiatry 174:95-100
14. Schotte CKW, de Doncker D (1994) ADP-IV Questionnaire. University Hospital Antwerp, Antwerp

15. Doering S, Renn D, Hofer S, Rumpold G, Smrekar U, Janecke N, Schatz DS et al (2007) Validation of the German version of the assessment of DSM-IV personality disorders (ADP-IV) questionnaire. Z Psychosom Med Psychother 53:111-128

16. Schotte CKW, de Doncker D, Vankerckhoven C, Vertommen H, Cosyns P (1998) Self-report assessment of the DSM-IV personality disorders. Measurement of trait and distress characteristics: the ADP-IV. Psychol Med 28:1179-1188

17. Schotte CKW, de Doncker DA, Dmitruk D, Van Mulders I, D'Haenen H, Cosyns P (2004) The ADP-IV questionnaire: differential validity and concordance with the semi-structured interview. J Pers Disord 18:405-419

18. Schafer JL, Graham JW (2002) Missing data: our view of the state of the art. Psychol Methods 7:147-177

19. Hengartner MP, Ajdacic-Gross V, Rodgers S, Müller M, Rössler W (2013) Childhood adversity in association with personality disorder dimensions: new findings in an old debate. Eur Psychiatry. doi:10.1016/j.eurpsy.2013.04.004

20. Hengartner MP, Müller M, Rodgers S, Rössler W, Ajdacic-Gross V (2013) Can protective factors moderate the detrimental effects of child maltreatment on personality functioning? J Psychiatr Res. doi:10.1016/j.jpsychires.2013.05.005

21. Davidson G, Devaney J, Spratt T (2010) The impact of adversity in childhood on outcomes in adulthood: research lessons and limitations. J Soc Work 10:369-390

22. Gilbert R, Widom CS, Browne K, Fergusson D, Webb E, Janson S (2009) Burden and consequences of child maltreatment in highincome countries. Lancet 373:68-81

23. Haigler ED, Widiger TA (2001) Experimental manipulation of NEO-PI-R items. J Pers Assess 77:339-358

24. Samuel DB, Widiger TA (2010) A comparison of obsessivecompulsive personality disorder scales. J Pers Assess 92:232-240

25. Barrick MR, Mount MK, Judge TA (2001) Personality and performance at the beginning of the new millennium: what do we know and where do we go next? Int J Select Assess 9:9-30

26. Busato VV, Prins FJ, Elshout JJ, Hamaker C (2000) Intellectual ability, learning style, personality, achievement motivation and academic success of psychology students in higher education. Pers Individ Dif 29:1057-1068

27. De Fruyt F, Mervielde I (1998) Personality and interests as predictors of educational streaming and achievement. Eur J Pers $10: 405-425$

28. Widiger TA, Simonsen E, Krueger R, Livesley WJ, Verheul R (2005) Personality disorder research agenda for the DSM-V. J Pers Disord 19:315-338

29. Saulsman LM, Page AC (2004) The five-factor model and personality disorder empirical literature: a meta-analytic review. Clin Psychol Rev 23:1055-1085

30. Judge TA, Ilies R (2002) Relationship of personality to performance motivation: a meta-analytic review. J Appl Psychol 87:797-807

31. Michon HW, ten Have M, Kroon H, van Weeghel J, de Graaf R, Schene AH (2008) Mental disorders and personality traits as determinants of impaired work functioning. Psychol Med 38:1627-1637

32. Goodwin RD, Hoven CW, Lyons JS, Stein MB (2002) Mental health service utilization in the United States. The role of personality factors. Soc Psychiatry Psychiatr Epidemiol 37:561566

33. ten Have M, Oldehinkel A, Vollebergh W, Ormel J (2005) Does neuroticism explain variations in care service use for mental health problems in the general population? Results from the Netherlands mental health survey and incidence study (NEMESIS). Soc Psychiatry Psychiatr Epidemiol 40:425-431 
34. Bassett SS, Chase GA, Folstein MF, Regier DA (1998) Disability and psychiatric disorders in an urban community: measurement, prevalence and outcomes. Psychol Med 28:509-517

35. ten Have H, Vollebergh W, Bijl R, Ormel J (2002) Combined effect of mental disorder and low social support on care service use for mental health problems in the Dutch general population. Psychol Med 32:311-323

36. Tyrer P (2008) Personality disorder and public mental health. Clin Med 8:423-427

37. Miller JD, Pilkonis PA, Mulvey EP (2006) Treatment utilization and satisfaction: examining the contributions of axis II psychopathology and the five-factor model of personality. J Pers Disord 20:369-387

38. Rymaszewska J, Jarosz-Nowak J, Kiejna A, Kallert T, Schutzwohl M, Priebe S, Wright D et al (2007) Social disability in different mental disorders. Eur Psychiatry 22:160-166

39. Skodol AE, Pagano ME, Bender DS, Shea MT, Gunderson JG, Yen S, Stout RL et al (2005) Stability of functional impairment in patients with schizotypal, borderline, avoidant, or obsessivecompulsive personality disorder over two years. Psychol Med 35:443-451 